\title{
Recent updates in radioprotection
}

\section{Guy Frija ${ }^{1}$}

Received: 14 May 2020 / Revised: 18 June 2020 / Accepted: 21 July 2020 / Published online: 15 August 2020

(C) European Society of Radiology 2020

The 39 papers published last year in European Radiology and Insights into Imaging in the field of radiation protection represent a huge number, as does the strong increase over the years of the number of electronic posters submitted to ECRs. There are several reasons for this momentum: the basic safety standard (BSS), the most recent European regulation had to be transposed by February 2019, which was important. Furthermore, the development of dose reduction systems based on new technology or image processing, including artificial intelligence, is also a major contributor.

Publications released in 2019 were mostly dedicated to radiation dose optimization in adults, children, and pregnancy in both diagnostic and interventional procedures. There was a special interest for Diagnostic Reference Levels (DRL) establishment, using dose management systems and with some consideration of the clinical situation [1]. Variations in observed dose exposure in similar situations were pointed out, thus highlighting the need to further challenge variabilities in routine practice [2]. The EUCLID study reveals highly interesting findings [3] and should be published soon.

Dose reduction software as iteratively reported is very promising; however, the full impact is difficult to assess because it is considered separately and not in association. An approach integrating the parallel use of each of them might need to be further addressed.

Technological advances focus on dual-energy approaches, while photon-counting detectors are mostly overlooked, despite current significant development in Europe.

Research in the field of low dose is another major concern [4] and addresses several needs such as establishing European infrastructures, improving our understanding of the mechanisms of exposure effects in oncology and non-oncology changes, making dose measurement more accurate, and

Guy Frija

guyfrija@gmail.com

1 Paris Georges Pompidou European Hospital, Université Paris Descartes, Paris, France finally, implementing justification in clinical practice. The ongoing MEDIRAD project addresses these topics [5].

In radiation protection, justification and epidemiological risk assessment of low-dose exposure are critical issues. Not surprisingly, none is addressed. Implementation of the justification principle was certainly the weakest aspect of past European Directives output and remains a most challenging feature of BSS implementation today. Meanwhile, the initial dissemination of the ESR clinical decision support system (ESR iGuide) in Europe seems very promising, and we do hope to be reading reports of first experience soon. The risk of low-dose exposures health effect is still very much debated, in particular for children. Epi-CT is a multinational study funded by the European Commission [6], but the main conclusions we are eager to learn about are not published yet. Today, there is no consensus about established risks for the children and a regular overview of the literature on this topic would be welcome [7].

Most of the papers are from European teams. Comparison with studies performed outside of Europe would be highly interesting as routine practice might be different. One of the emerging concerns is about the increase of recurrent exposure. This is an example of these differences, as the magnitude of the phenomenon seems different when comparing two sides of the Atlantic, and the resulting recommendations should be adapted to the local setting [8]. EuroSafe Imaging is preparing recommendations to enhance the safety of patients undergoing recurrent imaging exams involving ionizing radiation.

Funding information The author states that this work has not received any funding.

\section{Compliance with ethical standards}

Guarantor The scientific guarantor of this publication is Guy Frija.

Conflict of interest The author of this manuscript declares no relationships with any companies, whose products or services may be related to the subject matter of the article.

Statistics and biometry No complex statistical methods were necessary for this paper. 
Informed consent Written informed consent was not required for this study because this work is an Editorial.

Ethical approval Institutional Review Board approval was not required because this work is an Editorial.

\section{Methodology}

- retrospective

- observational

\section{References}

1. Brat H, Zanca F, Montandon S et al (2019) Local clinical diagnostic reference levels for chest and abdomen CT examinations in adults as a function of body mass index and clinical indication: a prospective multicenter study. Eur Radiol 29:6794-6804

2. Euler A, Saltybaeva N, Alkadhi H (2019) How patient off-centering impacts organ dose and image noise in pediatric head and thoracoabdominal CT. Eur Radiol 29:6790-6793

3. EUCLID - European study on clinical diagnostic reference levels for X-ray medical imaging. http://www.eurosafeimaging.org/euclid. Accessed 2020
4. European Association of Nuclear Medicine (EANM), European Federation of Organizations for Medical Physics (EFOMP), European Federation of Radiographer Societies (EFRS), European Society of Radiology (ESR), European Society for Radiotherapy and Oncology (ESTRO) (2017) Common strategic research agenda for radiation protection in medicine. Insights Imaging 8:183-197

5. MEDIRAD. Implications of medical low dose radiation exposure. http://www.medirad-project.eu

6. Bernier MO, Baysson H, Pearce MS et al (2019) Cohort profile: the EPI-CT study: a European pooled epidemiological study to quantify the risk of radiation-induced cancer from paediatric CT. Int $\mathrm{J}$ Epidemiol 48(2):379-381g. https://doi.org/10.1093/ije/dyy231

7. Sheppard JP, Nguyen T, Alkhalid Y, Beckett JS, Salamon N, Yang I (2018) Risk of brain tumor induction from pediatric head CT procedures: a systematic literature review. Brain Tumor Res Treat 6(1):1-7

8. Brambilla M, Vassileva J, Kuchcinska A, Rehani MM (2020) Multinational data on cumulative radiation exposure of patients from recurrent radiological procedures: call for action. Eur Radiol 30: 2493-2501. https://doi.org/10.1007/s00330-019-06528-7

Publisher's note Springer Nature remains neutral with regard to jurisdictional claims in published maps and institutional affiliations. 